\title{
History of Erythropoiesis-Stimulating Agents, the Development of Biosimilars, and the Future of Anemia Treatment in Nephrology
}

\author{
Kamyar Kalantar-Zadeh \\ Harold Simmons Center for Kidney Disease Research and Epidemiology, University of California-Irvine, \\ School of Medicine, Orange, CA, USA
}

\section{Keywords}

Erythropoiesis-stimulating agents - Biosimilar · Chronic kidney disease

\begin{abstract}
Background: Exogenous replacement of erythropoietin (EPO) by recombinant human EPO has been considered a standard of care for the treatment of anemia in patients with chronic kidney disease for more than 20 years. Genetically engineered biologic proteins derived from human, animal, or microorganism sources are a major area of growth in modern medical care, accounting for one-third of new drug approvals in the past decade. Despite benefit to patients, the use of biologics comes at a significant cost, representing one of the fastest growing segments of strained healthcare budgets around the world. Summary: Biosimilars, or biologic drugs that are designed to be highly similar to approved reference biologic drugs, have been available in Europe for more than 10 years with no unusual or unexpected effects compared to their reference biologics whose patents have expired. Given the success of the biosimilar approval pathway pioneered in Europe, it has served as a global reference for other regulatory authorities to establish and implement biosimilar licensure frameworks, including the United States (US), the largest pharmaceutical market in the world. Given 10 of the top 25 drugs sold in 2014 were biologics, and con-
\end{abstract}

(C) 2017 S. Karger AG, Basel

\section{E-Mail karger@karger.com \\ www.karger.com/ajn \\ KARGER}

sidering the rising costs of healthcare, biosimilars have the potential to become a significant part of the US market. Key Messages: For the nephrology community, the recent patent expiries for epoetin alfa (Epogen ${ }^{\circledR}$, Amgen and Procrit $^{\circledR}$, Johnson \& Johnson) have created the opportunity to develop biosimilar EPOs. And while no biosimilar in this therapeutic class is approved in the US, there are proposed biosimilars in development.

(c) 2017 S. Karger AG, Basel

\section{Erythropoietin and Erythropoiesis-Stimulating Agents: A Historical Perspective}

Erythropoietin (EPO) is an amino acid glycoprotein hormone synthesized and secreted by interstitial cells to stimulate the production of red blood cells in the bone marrow in response to falling levels of oxygen in the tissues. Human $E P O$ was first isolated from the urine of anemic patients in 1977 [1], and its gene was later isolated in 1983 [2]. One year later, 2 groups succeeded in cloning the $E P O$ gene and expressing it in Chinese hamster ovary $(\mathrm{CHO})$ cells, enabling development of recombinant human EPO (rHuEPO) as a drug [3]. Briefly, the genetic engineering of $\mathrm{rHuEPO}$ is as follows: (1) identification of the gene that produced EPO; (2) isolation of the gene; (3) introduction of the gene into $\mathrm{CHO}$ cells; (4) production

Kamyar Kalantar-Zadeh, MD, MPH, PhD

Division of Nephrology and Hypertension, University of California-Irvine

Suite 400, 101 The City Drive South, City Tower

Orange, CA 92868 (USA)

E-Mail kkz@uci.edu 


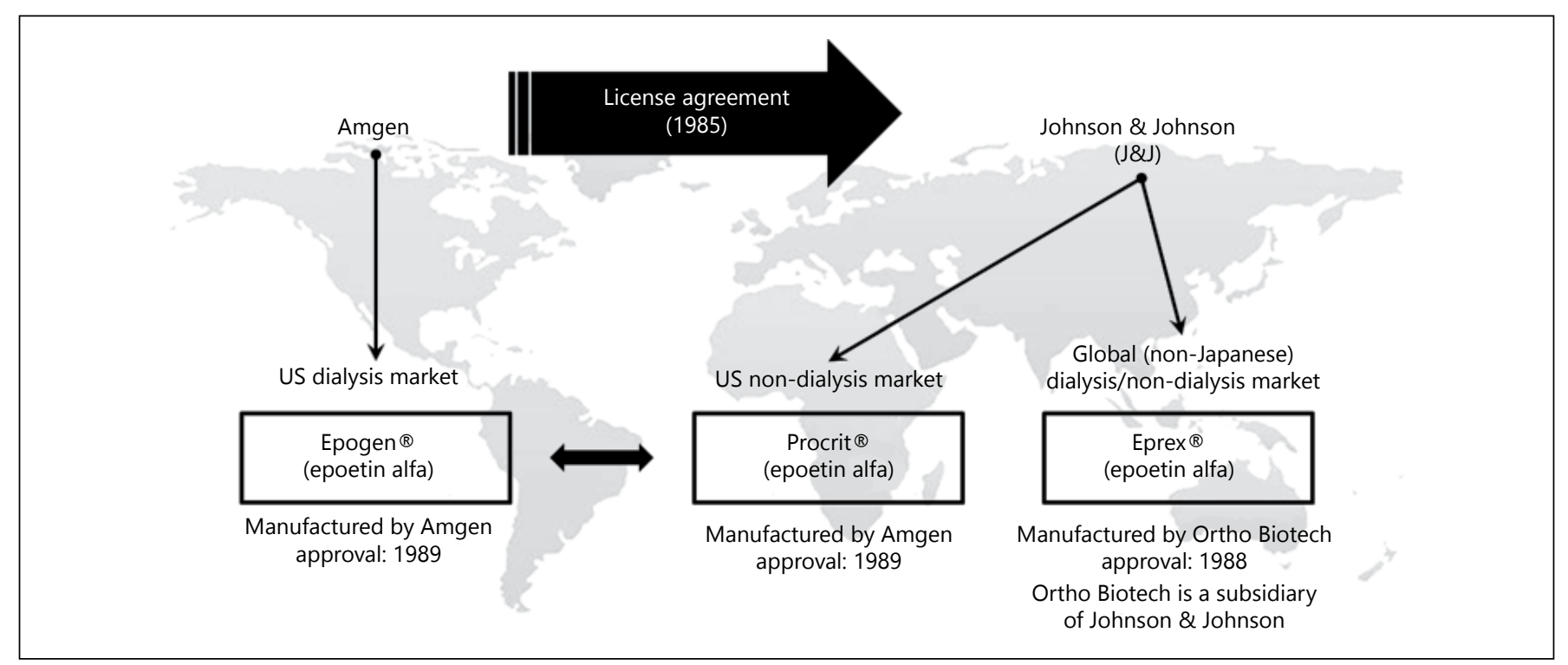

Fig. 1. Technology transfer of epoetin alfa.

of rHuEPO in CHO cells; and (5) purification of rHuEPO in a stable and biologically active form.

Anemia is a common complication of advanced chronic kidney disease (CKD). Whereas the pathogenesis of anemia of CKD is multifactorial, the decreased production of EPO with declining renal mass is considered the primary etiologic factor [4]. Anemia is associated with fatigue, weakness, and dyspnea, as well as worsening quality of life and performance status. Exogenous replacement of EPO by rHuEPO, along with iron, quickly became a standard of care for the treatment of anemia in patients with CKD after the isolation of introduction of the EPO gene into CHO cells [4].

The first rHuEPO, epoetin alfa, was manufactured by Amgen and sold as Epogen ${ }^{\circledR}$ in the United States (US) for dialysis patients (in 1989). In 1985, Amgen transferred rights for all non-dialysis indications in the US and all indications outside the US (excluding Japan) to Johnson \& Johnson, and its affiliate Ortho Biotech, in a long-standing licensing agreement [3]. Since then Ortho Biotech has been marketing the same epoetin alfa manufactured by Amgen in the US under the brand name, Procrit ${ }^{\circledR}$. After a technology transfer, Ortho Biotech began to manufacture epoetin alfa in its own facility in Puerto Rico and sells it in most markets outside the US under the brand name, Eprex ${ }^{\circledR}$. Amgen licensed epoetin alfa to Kirin Brewery in Japan, which manufactures epoetin alfa in its own plant after a similar technology transfer. Figure 1 provides a visual interpretation of the technology transfer for epoetin alfa.
The first non-alfa EPO - epoetin beta - was developed by Genetics Institute and manufactured initially by Boehringer Mannheim, and approved in Europe as brand name Recormon ${ }^{\circledR}$ in 1990 , shortly after the introduction of Eprex in 1988. The naming of Recormon followed the World Health Organization (WHO) guidelines; analogues of epoetin are classified by a Greek letter after epoetin to differentiate between products of the same amino acid sequence which vary in the glycosylation pattern [5]. In 1997, NeoRecormon ${ }^{\circledR}$ (epoetin beta) was reintroduced in Europe by Roche as an optimized formulation of Recormon, with small changes in the content of excipients to accommodate the lyophilized drug presentation and enable a more convenient subcutaneous administration [6].

Key to the development of the first competitive rHuEPO marketplace was the patent debate regarding EPO, one of the largest and lengthiest legal battles known to the pharmaceutical industry. Genetics Institute and Amgen both obtained patents in the US relating to EPO in 1987; Genetics Institute in July with the "composition of matter" patent and a liquid chromatography-based process for producing it, and Amgen in October with a patent for the EPO DNA sequence and a recombinant DNA process for manufacturing it [7]. Genetics Institute's method of EPO production was to isolate it from urine, thus making it unviable to produce mass quantities needed for the market. On the other hand, Amgen's patent for the mode of EPO production made 
it commercially viable to produce the substance, although the patent from Genetics Institute was a legal barrier for Amgen to use the starting materials to synthesize EPO. Thus, neither Genetics Institute nor Amgen had the ability to commercialize EPO without infringing the other's patents.

The litigation and legal proceedings, which lasted nearly 8 years, concluded with a final ruling in Amgen's favor in 1995 [8]. In short, the Courts found the Genetics Institute patent to provide an inadequate description of a generic method for obtaining human EPO, and thus, there was no evidence that Genetics Institute had isolated the protein with the biological profile described in the patent. Genetics Institute sought a patent on the recombinant production of EPO in Europe and was awarded such in May 1991 with the rights acquired by Boehringer Mannheim (later Roche) [9]. This patent would become the basis for the development of epoetin beta.

As short-acting drugs, first generation EPO required frequent dosing to maintain adequate hemoglobin levels, given a half-life of approximately $8 \mathrm{~h}$. "Next generation EPOs," including darbepoetin alfa and a pegylated version of epoetin beta, were developed with altered structures, extending the elimination half-life of the drug and reducing the dose schedule necessary for hemoglobin maintenance, which ranged from once weekly to once monthly depending on the indication in CKD. Darbepoetin alfa (Aranesp ${ }^{\circledR}$ ) was developed by Amgen as a modified hyperglycosylated epoetin; a 5 amino acid substitution at select sites allows for hypersialyation. Aranesp was approved by the Food and Drug Administration (FDA) and European Medicines Agency (EMA) bringing competition to Procrit in the US and to epoetin beta in Europe in 2001. Methoxy polyethylene glycol epoetin beta (Mircera ${ }^{\circledR}$ ), developed by Roche, incorporated a large pegylated polymer chain into the epoetin structure to substantially increase the molecular weight of the drug $(30.4-60 \mathrm{kDa})$. Mircera was approved by the FDA and EMA in 2007, although it was not marketed in the US for an additional 7 years due to intellectual property constraints [10].

Based on the terms of the original licensing agreement for Epogen, Johnson \& Johnson commenced arbitration with Amgen to obtain the rights to Aranesp after its approval by the FDA in 2001. Johnson \& Johnson contended that the company was to be given exclusive rights to the improvements of epoetin alfa made by Amgen regarding its development of Aranesp. Johnson \& Johnson believed their licensing agreement included Aranesp, and

Future of ESAs and Biosimilars as such, claimed that Amgen should not be allowed to market the drug in non-dialysis indications. Amgen disagreed with the claim, citing Aranesp as a unique drug covered by different patents and outside the context of the licensing agreement. Amgen prevailed in arbitration and kept the sole rights to Aranesp, allowing Amgen to enter the lucrative non-dialysis market in the US $[11,12]$.

Amgen was also engaged in litigation with Roche regarding the US marketing of Mircera. Amgen claimed that pegylated epoetin beta was in violation of multiple patents held by Amgen relating to $\mathrm{rHuEPO}$ as well as processes to manufacture the drug. Amgen sought an injunction to prevent Mircera from being imported and marketed in the US until the patent expiry of epoetin alfa. The court ruled in Amgen's favor and Roche was barred from selling Mircera in the US until mid-2014 under terms of a limited license agreement [10]. In May 2015, Roche entered into an exclusive license agreement for the commercialization of Mircera in the US with Galenica [13]. Table 1 provides a brief summary of first and next generation erythropoiesis-stimulating agent (ESA) products.

\section{Safety of ESAs}

The safety of recombinant human ESAs has been a well-covered topic in the last 10 years. In particular, concerns regarding pure red cell aplasia (PRCA) and increased cardiovascular (CV)-related adverse events have been of great interest to the nephrology community and are relevant to the development of new ESAs. The sudden appearance outside the US of patients presenting with antibody-mediated PRCA in the late 1990s, primarily associated with subcutaneous administration of Eprex, highlighted the potential consequence of manufacturing changes on product safety [14]. Furthermore, several CV outcome-related studies pointed to an increase in $\mathrm{CV}$ adverse events associated with higher hemoglobin targets and the increasing doses of ESAs required in achieving those targets $[15,16]$. As a consequence, the FDA (as well as other regulatory bodies around the world) stipulated a warning in 2007 for all ESAs prompting clinicians to use the lowest dose of drug in patients to maintain adequate hemoglobin levels [17].

\section{Pure Red Cell Aplasia}

A small number of case reports of an antibodymediated form of PRCA associated with ESA therapy began to appear in the literature around the mid-1990s, but 
Table 1. Summary of erythropoiesis-stimulating agents

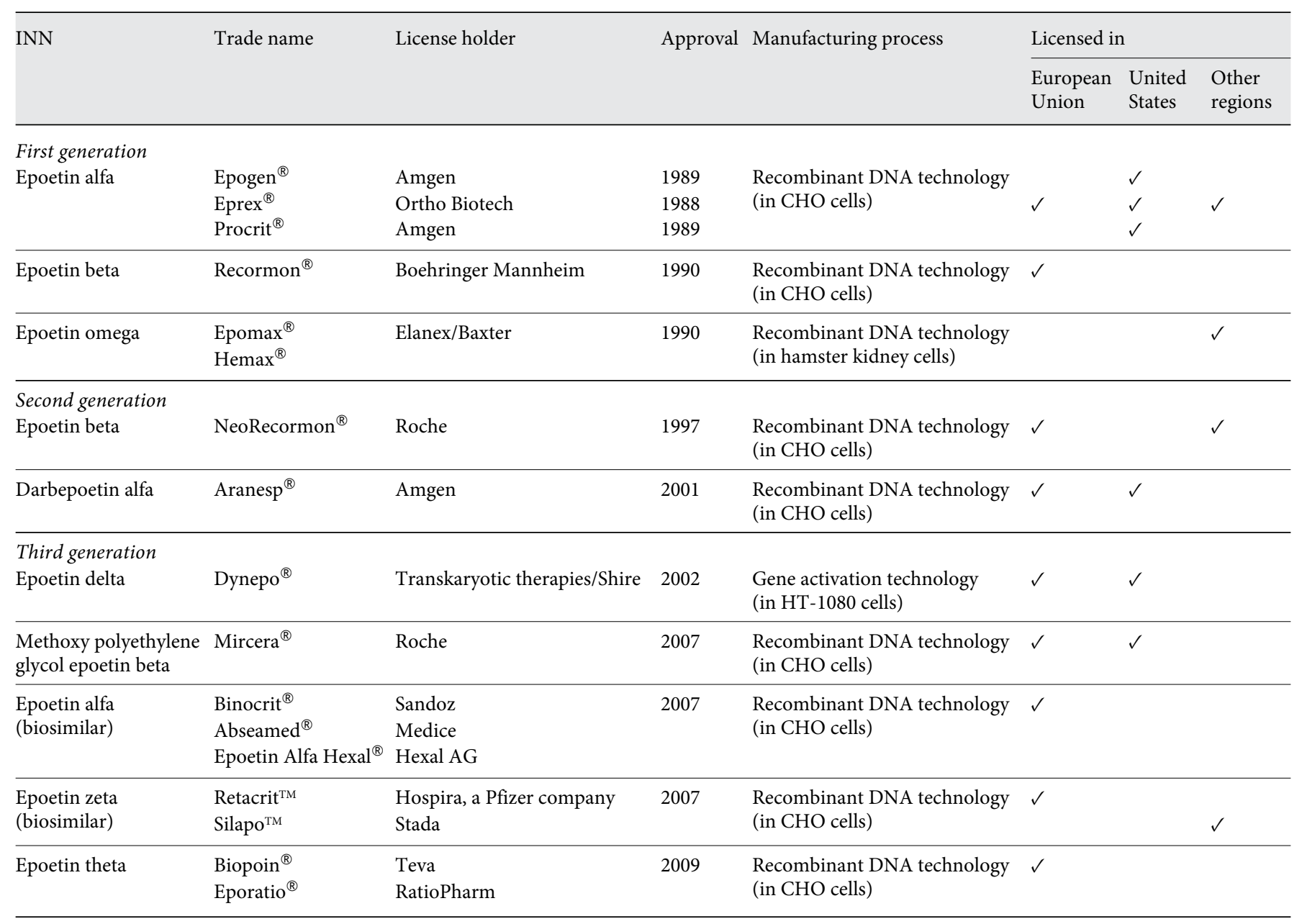

INN, international nonproprietary name; NCE, new chemical entity; NME, new molecular entity.

the complication did not receive much attention until an "epidemic" of ESA-associated PRCA occurred between 1998 and 2004 [18]. In 1998, Johnson \& Johnson, the manufacturer of Eprex, changed the stabilizing agent of the product from human serum albumin to polysorbate 80 and glycine, prompted by European concern about the potential for transmission of Creutzfeldt-Jakob disease [14]. After much study, it was hypothesized that the polysorbate 80 may have increased the immunogenicity of Eprex by eliciting formation of epoetin-containing micelles or by interacting with leachates released by the uncoated rubber stoppers of prefilled syringes for subcutaneous administration [19]. Compared with the previous formulation, the polysorbate 80 formulation had a lower stability, making it more susceptible to stress conditions (e.g., insufficient attention to the cold chain). This situation may have facilitated protein denaturation or aggregate formation [20].

From 1999 to 2002, global reports of antibodymediated PRCA increased with more than 60 cases of PRCA reported with Eprex per year [18]. In December 2002, health authorities in Europe formally contraindicated subcutaneous administration of Eprex for patients with CKD $[19,21]$. The incidence of PRCA returned to historical low rates by 2003 after Johnson \& Johnson replaced the uncoated rubber stoppers with Teflon stoppers in the prefilled syringes, supported intravenous administration of the product, and improved cold chain storage management $[14,20]$. The contraindication for subcutaneous administration of Eprex was later removed in 2006 after completion of the PRIMS study, which showed that rates of PRCA had returned to the expected background 
incidence [19]. As treatment with ESAs were rarely "switched" during this time period, it is likely that identification of the source of immunogenicity in patients receiving Eprex was the result of a common treatment pattern by nephrologists.

Although the dramatic spike in PRCA cases has decreased since the early 2000s, a small number of cases have continued to be reported worldwide, almost all of them being associated with subcutaneous administration. Although intravenous administration of a protein is less likely to evoke an immune response than the subcutaneous route, $\mathrm{PRCA}$ with intravenous administration of epoetin has been reported in the literature, including a case in Japan where a patient received both epoetin alfa and darbepoetin alfa [22]. Two additional cases of PRCA with intravenous epoetin have been described, but follow-up did not preclude the subcutaneous route of administration [23]. Furthermore, several cases of PRCA have also been reported following the use of epoetin "copy" biologics in regions where there are less rigorous regulations regarding product storage and manufacturing [20].

\section{Increase in CV Events}

The use of blood transfusions and androgenic steroids for the treatment of anemia in patients with CKD was supplanted by ESAs, likely the result of improved quality of life in early studies involving EPO and CKD. As the link between $\mathrm{CV}$ disease and CKD became more evident, it became clear that anemia was an independent risk factor for developing left ventricular hypertrophy and heart failure. However, in the absence of well-controlled studies, ESAs became the mainstay to treat anemia while the optimal level of hemoglobin to limit CV events remained unknown. Between 1991 and 2005, the mean ESA dose increased about 4-fold in dialysis patients in the US [24].

Following reports of increased adverse events from outcomes studies, such as CV events and more frequent hypertensive episodes when using higher doses of ESAs to achieve higher hemoglobin targets, the FDA mandated a black box warning for all ESAs in 2007 [17]. The decision was based on key data obtained from the Normal Hematocrit Cardiac Trial (NHCT) [25], the Correction of Hemoglobin and Outcomes in Renal Insufficiency (CHOIR) study [15], and the Cardiovascular Risk Reduction by Early Anemia Treatment with Epoetin Beta (CREATE) study [16]. Briefly, the results of NHCT pointed to an increase in vascular access thrombosis and a trend toward death and heart attacks among dialysis patients in the higher hematocrit arm, while the CHOIR study confirmed an increased risk of a composite end point including death and CV events among predialysis patients targeted to higher hematocrit levels. The CREATE study did not demonstrate differences between patients assigned to either full or partial correction of anemia in terms of CV events, but a prespecified secondary analysis showed a higher risk of end-stage renal disease requiring dialysis among the patients with the higher target for hemoglobin concentration. More recent studies, including the Trial to Reduce Cardiovascular Events with Aranesp Therapy and the subanalysis of the Reduction of Events by Darbepoetin Alfa in Heart Failure study, reinforce the aforementioned data and demonstrate the correction of anemia in CKD patients with ESAs does not confer a beneficial effect on mortality, CV, or renal outcomes $[26,27]$.

\section{The Dawn of Biosimilars}

As noted, biologics are genetically engineered proteins derived from human, animal, or microorganism sources. They are a major area of growth in the medical community, accounting for one-third of new medicine approvals in the past decade [28]. As of 2013, the Pharmaceutical Research and Manufacturers of America reported more than 900 biologics in development [28]. Biologics play an integral and often transformative role in many therapeutic settings, and guidelines from medical societies and payer groups have incorporated biologics into recommended treatment regimens, either as primary or supportive care [4].

Despite the immense therapeutic benefit conferred to patients, the growing use of biologics comes at a significant cost, representing one of the fastest growing segments of stretched healthcare budgets around the world [29]. Unlike small molecule drugs, synthesized by chemically reproducible processes, biologics are genetically engineered proteins that are produced by living systems and have inherent variability. Due to the large and structurally complex molecules that comprise biologics, as well as differences in cell lines and processes used during manufacturing, "identical" copies of biologics cannot be developed. Thus, a similar copy of a biologic drug, a "biosimilar," is not to be regarded as a generic version of a currently approved biologic. Rather, a biosimilar is a biologic drug that is highly similar to an approved reference biologic drug. The high level of similarity to the reference product includes the same primary structure, mechanism of action, and drug target, among other physiochemical similarities, based on the results of an extensive comparabil- 
ity exercise which includes clinical confirmation of pharmacokinetics and pharmacodynamics outlined by regulatory authorities $[30,31]$. A product that does not meet these standards cannot be approved as a biosimilar.

For biosimilars to achieve full acceptance in global markets, it is crucial that they be considered analytically, pharmacokinetically, and therapeutically equivalent with their reference product. Thus, biosimilars must go through a rigorous development process and comparability exercise, and demonstrate no clinically significant differences in safety, purity, and potency compared to the reference product. Given the inherent variability of a biologic compared with a small molecules drug and acknowledging a biosimilar cannot be "identical" to a reference biologic product (which itself is structurally variable from batch to batch), regulatory authorities recognized the need for a unique approval pathway for biosimilars distinct from generics.

The European Union (EU) was the first to establish a specific regulatory pathway for biosimilars. In 2001, Directive 2001/83/EC provided the legal basis for approval of biosimilars in the EU. The directive allowed the EMA to draft the first biosimilar guideline and publish in 2005, after resolution of the Eprex PRCA outbreak. The guideline outlined the basic principles of the EU biosimilar regulatory approach by specifically demonstrating similarity of a biosimilar with its reference product in terms of quality, safety, and efficacy through analytical and clinical studies [32]. One year later, the EMA adopted biosimilar guidelines to address issues in analytical studies (e.g., selection of a reference product, methods, and product characterization, and demonstration of biological activity and purity) as well as nonclinical and clinical studies (e.g., pharmacotoxicological assessment, pharmacokinetics, efficacy, and safety) [33]. An additional guideline tackled the need for post-approval safety monitoring and a risk management plan that highlights immunogenicity [34]. The EMA has also developed class-specific guidelines for recombinant EPOs, interferon $\beta$, and, more recently, monoclonal antibodies [34-36]. Of note is the significant role that the outbreak of PRCA, after a manufacturing change with Eprex, played in development of the biosimilar guidelines for EPO.

Interestingly, the definition of a biosimilar is not a consensus by regulatory authorities and each country adopts its own (Table 2). In 2009, the WHO published a guideline that presents globally acceptable principles to license biosimilars that can be adapted to meet the needs of regulatory authorities in countries with no published guidance [37]. The guideline is thought to be an initial step in the harmonization to evaluate and regulate bio- similars, and several countries have adopted its principles to elaborate their own guidelines, including Canada, South Korea, and Brazil to name a few [38]. Despite the existence of slight differences in the scope of available guidelines, the basic principles governing regulatory requirements for biosimilars are of a similar nature across different nations $[38,39]$. This generally includes preclinical and clinical comparability studies to demonstrate safety and efficacy as well as post-manufacturing assays to examine immunogenicity.

To date, the experience with biosimilars has been generally limited to the following 4 therapeutic classes: granulocyte colony-stimulating factors, epoetins, monoclonal antibodies, and human growth hormones. The first biosimilar approved in Europe was somatropin (2006), followed by EPO (2007), filgrastim (2008), infliximab (2013), follitropin alfa (2013), insulin glargine (2014), and most recently, etanercept (2016). To date, 21 biosimilars have market authorization from the EMA; this includes several similar drug substances being co-marketed under different trade names [40].

The use of biosimilars has slowly, but steadily, increased since reaching the European market 8 years ago. Historical data for biosimilars indicate that market penetration varies by class [41]. Reported differences in the adoption of biosimilars appear to be country-specific, suggesting different regional incentives [42]. For example, 4 years after first launch, the use of biosimilar epoetins has outpaced first and second generation epoetins in Sweden and Germany, but uptake in Italy, France, and the United Kingdom has lagged behind [43]. Amid limited price discounting in some countries, it has also been hypothesized that the slow uptake of biosimilars is due to concerns of efficacy and safety, including immunogenicity, hypersensitivity, and increased risk for other adverse effects, by physicians and patients [44]. Despite these concerns, no unusual or unexpected effects have occurred with use of biosimilars compared to reference biologics in Europe [45].

\section{Biosimilar ESAs in Europe}

The guidelines for quality requirements for a biosimilar product, published by the Committee for Medicinal Products for Human Use (CHMP), state that the active substance in the biosimilar should be similar to the one in the reference product. The general nonclinical and clinical requirements for a biological product claiming to be similar to an approved biopharmaceutical are similar to the requirements for a reference product, and evalua- 
Table 2. Biosimilar terminology according to regulatory authorities

\begin{tabular}{|c|c|c|c|}
\hline Region/country & Agency & Term & Definition \\
\hline Europe & EMA & Biosimilar & $\begin{array}{l}\text { A biological medicinal product that contains a version of the } \\
\text { active substance of an already authorized original biological } \\
\text { medicinal product (reference medicinal product). Similarity to the } \\
\text { reference medicinal product in terms of quality characteristics, } \\
\text { biological activity, safety and efficacy based on a comprehensive } \\
\text { comparability exercise needs to be established. }\end{array}$ \\
\hline Global & WHO & Similar biotherapeutic product & $\begin{array}{l}\text { A biotherapeutic product similar to an already licensed reference } \\
\text { biotherapeutic product in terms of quality, safety and efficacy. }\end{array}$ \\
\hline US & FDA & Follow-on biologic or biosimilar & $\begin{array}{l}\text { A biological product that is highly similar to a US-licensed } \\
\text { reference biological product notwithstanding minor differences in } \\
\text { clinically inactive components, and for which there are no clinically } \\
\text { meaningful differences between the biological product and the } \\
\text { reference product in terms of the safety, purity, and potency of the } \\
\text { product. }\end{array}$ \\
\hline Canada & $\begin{array}{l}\text { Health } \\
\text { Canada }\end{array}$ & Subsequent-entry biologic & $\begin{array}{l}\text { A biologic product that is similar to and would enter the market } \\
\text { subsequent to an approved innovator biologic product. }\end{array}$ \\
\hline Korea & MFDS & Biosimilar & $\begin{array}{l}\text { Biological products which demonstrated its equivalence to an } \\
\text { already approved reference product with regard to quality, safety, } \\
\text { and efficacy. }\end{array}$ \\
\hline Brazil & ANVISA & Biologic product & $\begin{array}{l}\text { A biologic medicine with known biologic activity that contains no } \\
\text { new molecules, already licensed in Brazil and that has gone through } \\
\text { all the production steps (including formulation, vialing, freeze } \\
\text { drying, labeling, packaging, storage, quality control and biologic } \\
\text { product lot release. }\end{array}$ \\
\hline
\end{tabular}

ANVISA, Agencia de Vigilancia Sanitaria; EMA, European Medicines Agency; FDA, Food and Drug Administration; MFDS, Ministry of Food and Drug Safety; US, United States; WHO, World Health Organization.

tion is mainly based upon data obtained by comparative studies, biosimilar vs. reference product. For a CHMP application of a biosimilar EPO, nonclinical studies comprise pharmacodynamic and toxiocologic assessments and the clinical studies include pharmacokinetic, pharmacodynamic, efficacy, and safety assessments (Table 3).

Currently, there are several biosimilar EPOs marketed in Europe by various license holders; however, these products represent only 2 biosimilar EPOs produced by 2 manufacturers: epoetin alfa (e.g., Binocrit ${ }^{\circledR}$, Sandoz) and epoetin zeta (e.g., Retacrit ${ }^{\circledR}$, Hospira, a Pfizer company). A summary of molecular differences between the biosimilar EPOs and their reference product can be found in a review by Jelkmann [46].

Details of the development programs for the approved biosimilar EPOs have been reviewed elsewhere [47]. Briefly, the approvals of biosimilar epoetin alfa and zeta in 2007 were based on robust nonclinical and clinical assessments including molecular characterization, preclin- ical in vivo and in vitro assays in animals, clinical studies in populations of interest, and pharmacovigilance surveillance studies. Overall, the available European data indicate an extensive population of patients with exposure to Retacrit without any unexpected adverse events [48]. And while the majority of exposure data are favorable for Binocrit, one confirmed case and another suspected case of PRCA in patients receiving subcutaneous Binocrit were reported during a clinical trial [49]. The manufacturer determined that tungsten species in the syringes may have caused Binocrit protein to unfold, with subsequent formation of aggregates [50]. The tungsten was thought to originate from tungsten pins used to form the barrels of the glass syringes in which the final product is provided. As a result, Binocrit is now only available for the intravenous indication, while Retacrit is available for both intravenous and subcutaneous indications. To date, there is no evidence for an increase in PRCA or other untoward adverse events among biosimilar ESAs. 
Table 3. CHMP erythropoietin biosimilar application requirements

\begin{tabular}{|c|c|c|}
\hline Assessment type & Requirements & \\
\hline $\begin{array}{l}\text { Nonclinical } \\
\text { Pharmacodynamic }\end{array}$ & In vitro (receptor binding, cell proliferation) & In vivo (comparison of erythrogenic effects) \\
\hline Toxiocologic & $\begin{array}{l}\text { Repeat dose toxicity in a relevant species, duration of at } \\
\text { least } 4 \text { weeks }\end{array}$ & Local tolerance in a relevant species \\
\hline Pharmacodynamic & $\begin{array}{l}\text { Evaluated as part of the PK assessments, selected dose } \\
\text { should be in the linear ascending part of the dose-response } \\
\text { curve }\end{array}$ & Healthy volunteers \\
\hline Safety & $\begin{array}{l}\text { Comparative safety data, adverse events of special interest } \\
\text { include hypertension/aggravation of hypertension and } \\
\text { thromboembolic events }\end{array}$ & $\begin{array}{l}\text { 12-month comparative immunogenicity } \\
\text { assessment }\end{array}$ \\
\hline
\end{tabular}

CHMP, Committee for Medicinal Products for Human Use; PK, pharmacokinetic.

\section{Emerging Opportunities for Biosimilar ESAs in the US}

As the biosimilar approval pathway established in the EU has by and large been considered successful, it has served as a global reference for other regulatory authorities in other parts of the world, including the US. The Patient Protection and Affordable Care (PPAC) Act, signed into law in March 2010, amended the Public Health Service Act to create a separate licensure process for biologic products demonstrated to be biosimilar with an FDA-approved biologic product. As part of the PPAC Act, the Biologics Price Competition and Innovation (BPCI) Act created an abbreviated regulatory pathway for biosimilars via a $351(\mathrm{k})$ application. The pathway is designed to reduce the amount of testing required in animals and humans compared with reference biologics, which require a 351(a) Biologics License Application (Fig. 2) [51]. The advantage of the "totality of evidence" approach is the ability to leverage existing efficacy and safety data of the reference biologic, creating a more efficient development and approval process for biosimilars.

By definition from the FDA, approval of a biosimilar requires evidence that it is highly similar to its biologic reference product, notwithstanding minor differences in clinically inactive components, an it that produces no clinically meaningful differences from the reference product in terms of safety, purity, and potency based on comparative analytical and clinical studies [51]. In other terms, biosimilars must demonstrate high similarity to their reference product in analytical, nonclinical, and clinical environments. To be approved by the FDA, biosimilars must do the following: (1) exhibit the identical primary amino acid sequence as the reference biologic; (2) provide an extensive comparison of physiochemical and functional characteristics of the biosimilar to reference product; and (3) demonstrate comparable quality, safety, and efficacy in head-to-head preclinical and clinical trials (Fig. 3). Additionally, rigorous pharmacovigilance and post-marketing safety monitoring should take into consideration any particular safety concerns associated with the reference product and its therapeutic class as well as provide a mechanism to detect possible differences between the biosimilar and reference product, including new adverse effects not previously associated with the reference product.

After the passage of the PPAC Act, 3 draft policy documents were issued by the FDA in 2012 to provide clarity on the provisions of the BPCI Act, including exclusivity, biosimilarity, and interchangeability [52]; on various 


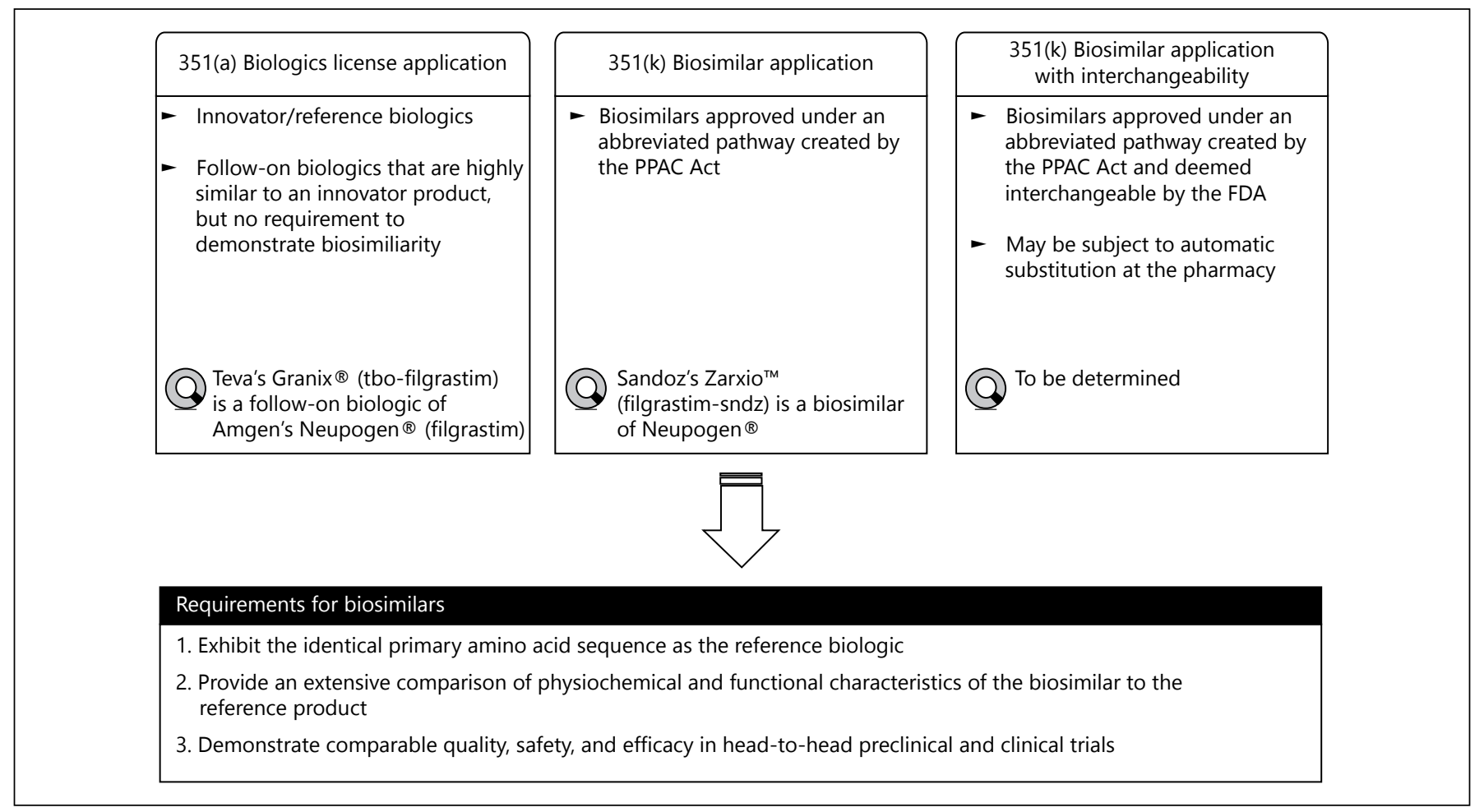

Fig. 2. Food and drug administration pathways for biosimilars. FDA, Food and Drug Administration; PPAC, Patient Protection and Affordable Care.

Fig. 3. Development of biosimilars in the United States. PK, pharmacokinetic; REMS, risk evaluation and mitigation strategies.

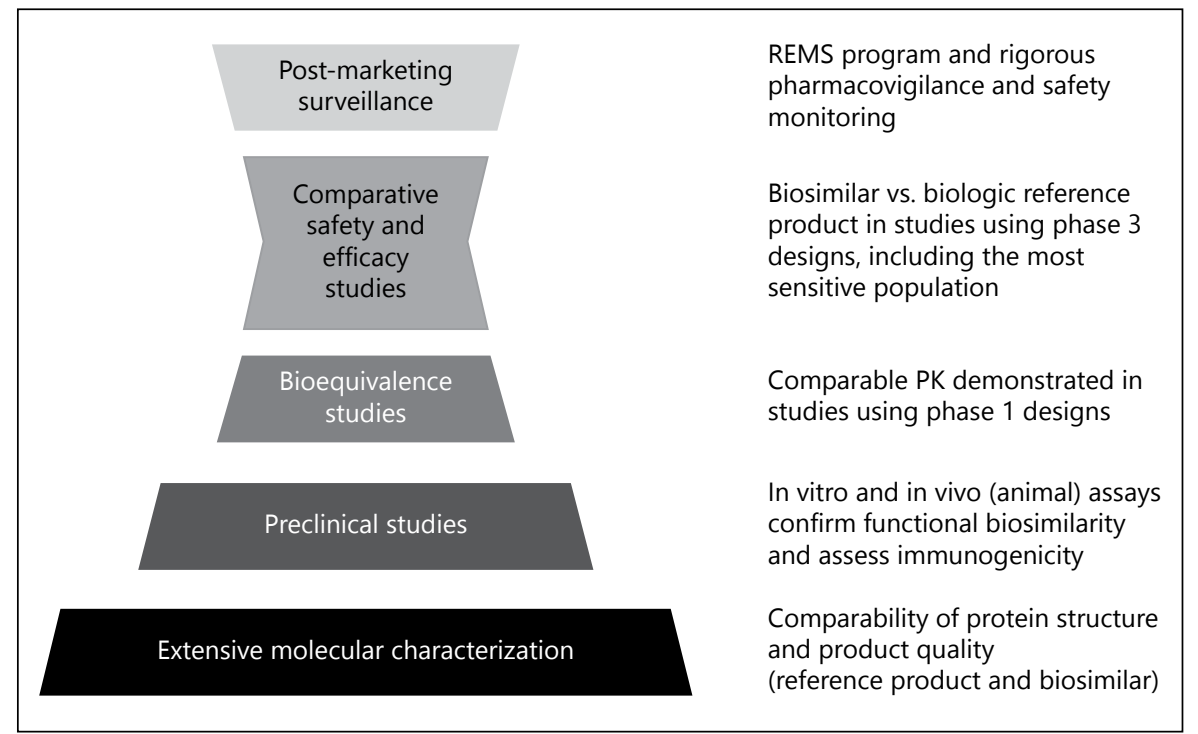

quality factors when characterizing a biosimilar [53]; and on scientific methods and data to demonstrate biosimilarity [54]. The policy documents were finalized by the FDA in March 2015, and 3 new draft documents were developed to discuss the use of clinical pharmacology data to support biosimilarity [55], reference product exclusivity [56], and labeling [57].

Unlike initial approval of generic drugs, additional evidence may be required before a biosimilar is approved as "interchangeable" with its reference product (Table 4) 
Table 4. Glossary of key terms

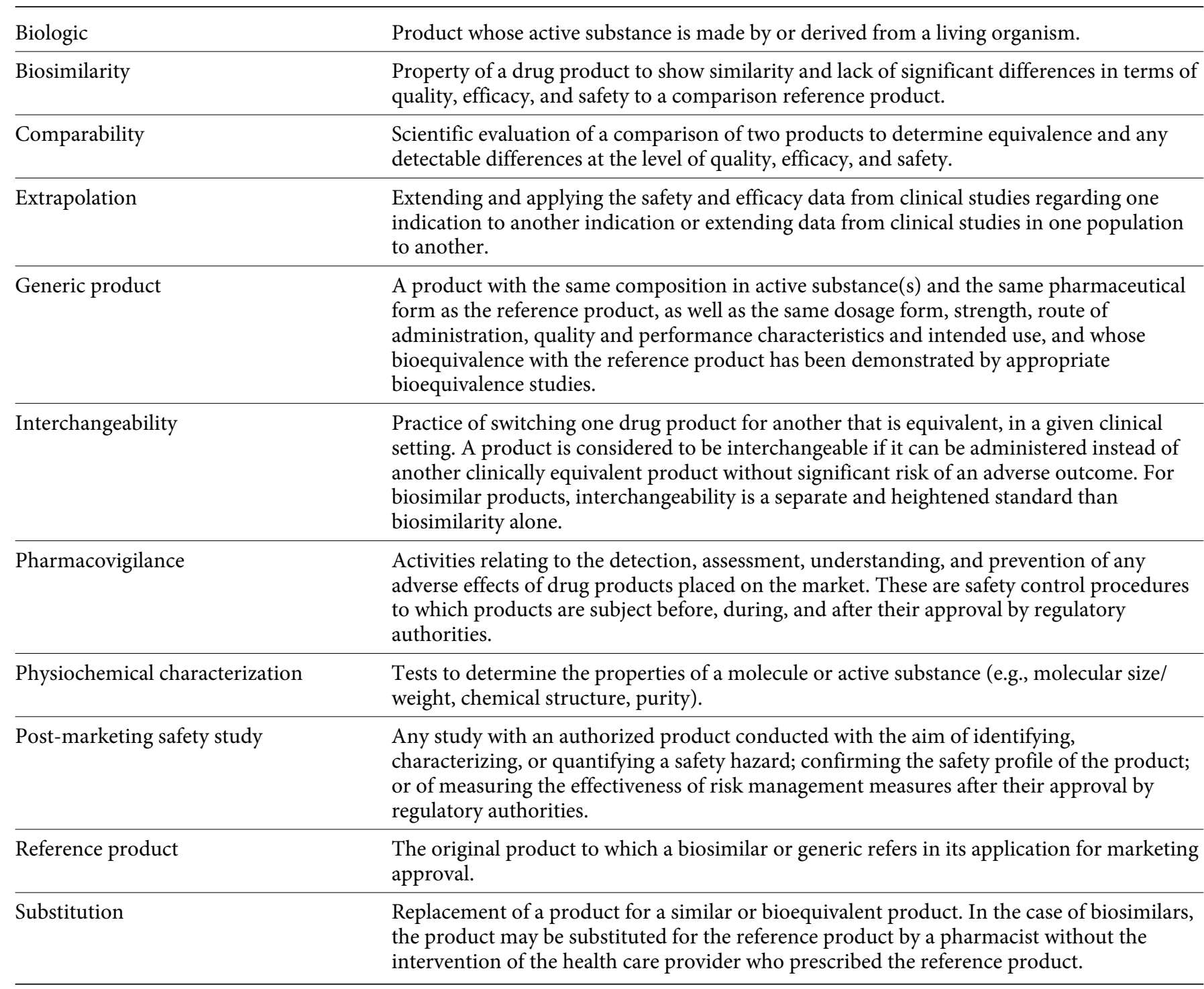

[53]. An interchangeability designation would allow for automatic substitution at the level of the pharmacy, and, thus, requires additional clinical evidence. Substitution regulations for interchangeable biosimilars will vary according to state pharmacy laws and the prescribing physician must be notified of all substitutions. The interchangeability designation is unique to the US.

Similar to other regulatory bodies, the FDA may extrapolate an indication that has not been formally investigated in a clinical trial for a biosimilar but that is approved for its reference product based on scientific justification. Also consistent is that robust safety monitoring of biosimilars will be necessary to track and record adverse effects, especially when considering the structural complexity and manufacturing differences make biosimilars susceptible to changes (like all biologics) that may affect safety (e.g., immunogenicity). The accuracy of postmarketing safety reports will partially depend on good traceability, which has not been an issue in Europe, where biosimilars traditionally have the same international nonproprietary name as the reference biologic, but unique brand names. One notable exception is epoetin zeta, a biosimilar of epoetin alfa. The debate over naming continues and may differ by country. Expert commentary regarding the approval process for biosimilar ESAs has been given by Wish [58] and Fishbane and Shah [59]. 
The FDA has received a number of 351(k) applications under the BPCI Act - Neupogen ${ }^{\circledR}$ (filgrastim) biosimilars from Sandoz and Apotex; a(n) Epogen/Procrit (epoetin alfa) biosimilar from Hospira, a Pfizer company; an Enbrel ${ }^{\circledR}$ (etanercept) biosimilar from Sandoz, a Humira ${ }^{\circledR}$ (adalimumab) biosimilar from Amgen; and Neulasta ${ }^{\circledR}$ (pegfilgrastim) biosimilars from Sandoz and Apotex. While the list is not exhaustive, as some organizations do not publicly announce filing activities, it demonstrates the uptick of submission activities for biosimilars in the US. In a landmark decision, the FDA Oncologic Drugs Advisory Committee unanimously recommended approval of Sandoz's filgrastim biosimilar (Zarxio $\left.{ }^{\mathrm{TM}}\right)$ in January 2015 - the first biosimilar to be approved in the US - and available as of September 2015 [60]. The FDA recently approved Celltrion's infliximab biosimilar (Inflecta $^{\mathrm{TM}}$ ) in April 2016 [61].

The patent expiries for epoetin alfa have opened the door of the US market to biosimilar epoetins. Hospira, a Pfizer company, and Sandoz have completed biosimilar registration programs including phase 3 clinical studies to support market authorization applications to support their biosimilar epoetins. Hospira filed a 351(k) application for Epoetin Hospira in December 2014 and received notification of filing acceptance from the FDA in February 2015. Hospira announced in October 2015 that they had received a response letter from the FDA in regards to Epoetin Hospira and were working closely with regulators to address the comments.

If approved, biosimilar ESAs could reduce a significant component of the nephrology budget (the bundled payment for dialysis), potentially increasing access to innovative new drugs or treatments. More broadly, given the high cost of other biologics reaching patent expiry, biosimilars may be capable of providing direct cost savings of up to $\$ 44$ billion dollars over the next 10 years [62]. At this juncture, the cost savings are theoretical estimates; any adjustments to the bundled payment schedule by Medicare will change the final savings.

\section{Conclusions}

For more than 20 years, exogenous replacement of EPO by rHuEPO has become a standard of care to treat anemia in patients with CKD. Key to the development of the early marketed rHuEPOs was the patent debates regarding EPO. Not surprisingly, the safety of these biologics has been of great interest to the nephrology community, including the incidence of PRCA in the late 1990s

and the upsurge in $\mathrm{CV}$ events corresponding with changes in rHuEPO treatment patterns.

Despite a benefit to patients, the use of biologics comes at a significant cost. A biosimilar is considered a therapeutic alternative to a reference biologic drug, demonstrating high similarity in terms of physiochemical and functional characteristics and clinical performance. Leveraging global experience and takeaways, biosimilars have the potential to improve access to treatment and help contain healthcare costs in the US. Future studies and observations, especially those from large registration post-marketing studies, will show the implications of ESA biosimilars in the US and emerging opportunities for patient care and research.

\section{Author Contributors}

The author actively engaged in each step of the manuscript process, including its development, critical review, and approval of the final version prior to submission. The author did not receive compensation for contributions to the manuscript.

\section{Acknowledgment}

The author extends thanks to Paul Audhya, MD, MBA, for review and editorial contributions during manuscript development. Research support, coordination assistance, and editorial support was also provided by Ms. Teresa A Oblak, PhD, CMPP of Covance Market Access Services Inc., which was funded by Hospira Inc. (acquired by Pfizer in September 2015).

\section{Disclosure Statement}

K.K.-Z. has received honoraria and/or support from Abbott, Abbvie, Alexion, Amgen, ASN, Astra-Zeneca, Aveo, Chugai, DaVita, Fresenius, Genentech, Haymarket Media, Hospira, Kabi, Keryx, NIH, NKF, Relypsa, Resverlogix, Sanofi, Shire, Vifor, and ZS-Pharma.

References

Am J Nephrol 2017;45:235-247

DOI: $10.1159 / 000455387$
1 Miyake T, Kung C, Goldwasser E: Purification of human erythropoietin. J Biol Chem 1977;252:5558-5563.

2 Lin FK, Suggs S, Lin CH, et al: Cloning and expression of the human erythropoietin gene. Proc Natl Acad Sci U S A 1985;82:75807584.

3 US Congress - Office of Technology Assessment. Recombinant Erythropoietin: Payment Options for Medicare, OTA-H-451. 1990. https://www.princeton.edu/ ota/ disk2/1990/9038/9038.PDF. 
4 KDIGO Working Group: KDIGO 2012 clinical practice guideline for the evaluation and management of chronic kidney disease. Kidney Int 2012;3:1-163.

5 World Health Organization: International Nonproprietary Names (INN) for Biological and Biotechnological Substances. http:// www.who.int/medicines/services/inn/ BioRev2013.pdf.

6 European Medicines Agency: Recormon EPAR. 2004. http://www.ema.europa.eu/ docs/en_GB/document_library/EPAR_-_ Scientific_Discussion/human/000116/ WC500024975.pdf.

7 Powell W, Brantley P: Magic bullets and patent wars: new product development and the evolution of the biotechnology industry; in Nishigunchi $T$ (ed): Managing Product Development. New York, Oxford University Press, 1996, pp 233-260.

8 Amgen, Inc. v Genetics Institute, Inc. CIV. A. No. 94-11818-WGY. 1995. http://www.leagle. com/decision/1995922877FSupp45_1915/ AMGEN,\%20INC.\%20v.\%20GENETICS\%20 INSTITUTE,\%20INC.

9 Rasmussen N: Gene Jockeys: Life Science and the Rise of the Biotech Enterprise. Baltimore, John Hopkins University Press, 2014.

10 Amgen: Amgen Resolves EPO Patent Dispute with Roche [Media Release]. 2009. http:// www.amgen.com/media/media_pr_detail. jsp?releaseID=1368916.

11 Aggarwal S: What's fueling the biotech engine? Nat Biotechnol 2007;25:1097-1104.

12 Bingham A, Spradlin D, Williams L, et al: Create Competitive Advantage with Innovation (Collection). Upper Saddle River, NJ, FT Press, 2011.

13 Roche: Roche Enters Into Exclusive License Agreement with Galenica for the Commercialisation of Mircerain the United States [Investor Update]. 2015. http://www.roche.com/investors/updates/inv-update-2015-05-28.htm.

14 Bennett CL, Luminari S, Nissenson AR, et al: Pure red-cell aplasia and epoetin therapy. N Engl J Med 2004;351:1403-1408.

15 Drueke TB, Locatelli F, Clyne $\mathrm{N}$, et al: Normalization of hemoglobin level in patients with chronic kidney disease and anemia. N Engl J Med 2006;355:2071-2084.

16 Singh AK, Szczech L, Tang KL, et al: Correction of anemia with epoetin alfa in chronic kidney disease. N Engl J Med 2006;355:2085-2098.

17 US Food and Drug Administration: Information for Healthcare Professionals: Erythropoiesis Stimulating Agents (ESA) [Aranesp (darbepoetin), Epogen (epoetin alfa), and Procrit (epoetin alfa)]. 2007. http://www.fda. gov/Drugs/DrugSafety/PostmarketDrug SafetyInformationforPatientsandProviders/ ucm126481.htm.

18 Macdougall IC: Antibody-mediated pure red cell aplasia (PRCA): epidemiology, immunogenicity and risks. Nephrol Dial Transplant 2005;20(suppl 4):iv9-iv15.

19 McKoy JM, Stonecash RE, Cournoyer D, et al: Epoetin-associated pure red cell aplasia: past, present, and future considerations. Transfusion 2008;48:1754-1762.

20 Macdougall IC, Roger SD, de Francisco A, et al: Antibody-mediated pure red cell aplasia in chronic kidney disease patients receiving erythropoiesis-stimulating agents: new insights. Kidney Int 2012;81:727-732.

21 Boven K, Stryker S, Knight J, et al: The increased incidence of pure red cell aplasia with an Eprex formulation in uncoated rubber stopper syringes. Kidney Int 2005;67:2346-2353.

22 Shimizu H, Saitoh T, Ota F, et al: Pure red cell aplasia induced only by intravenous administration of recombinant human erythropoietin. Acta Haematol 2011;126:114-118.

23 Cournoyer D, Toffelmire EB, Wells GA, et al: Anti-erythropoietin antibody-mediated pure red cell aplasia after treatment with recombinant erythropoietin products: recommendations for minimization of risk. J Am Soc Nephrol 2004;15:2728-2734.

24 National Institutes of Health, National Institute of Diabetes, Digestive and Kidney Diseases: USRDS 2006 Annual Data Report: Atlas of End-Stage Renal Disease in the United States. http://www.usrds.org/atlas06. aspx.

25 Besarab A, Bolton WK, Browne JK, et al: The effects of normal as compared with low hematocrit values in patients with cardiac disease who are receiving hemodialysis and epoetin. N Engl J Med 1998;339:584-590.

26 Pfeffer MA, Burdmann EA, Chen CY, et al: A trial of darbepoetin alfa in type 2 diabetes and chronic kidney disease. N Engl J Med 2009; 361:2019-2032.

27 Bello NA, Lewis EF, Desai AS, et al: Increased risk of stroke with darbepoetin alfa in anaemic heart failure patients with diabetes and chronic kidney disease. Eur J Heart Fail 2015; 17:1201-1217.

28 PhRMA: Medicines in Development: Biologics, 2013 Report. http://phrma.org/sites/default/files/pdf/biologicsoverview2013.pdf.

29 Singh SC, Bagnato KM: The economic implications of biosimilars. Am J Manag Care 2015; 21(16 suppl):s331-s340.

30 US Food and Drug Administration: Guidance for Industry: Scientific Considerations in Demonstrating Biosimilarity to a Reference product. 2012. http://www.fda.gov/downloads/Drugs/GuidanceComplianceRegulatoryInformation/Guidances/UCM291128. pdf.

31 European Medicines Agency: Guideline on similar biological medicinal products. 2013. http://www.ema.europa.eu/docs/en_GB/ document_library/Scientific_guideline/2013/05/WC500142978.pdf.

32 European Medicines Agency: Guideline on Similar Biological Medicinal Products. CHMP/437/04. 2005. http://www3.bio.org/ healthcare/followonbkg/GuidelineonSimilarBiologicalProducts.pdf.

33 European Medicines Agency: Guideline on Similar Biological Medicinal Products Containing Biotechnology-Derived Proteins as Active Substance: Quality Issues. EMA/ CHMP/BMWP/49348/2005. 2006. http:// www.ema.europa.eu/docs/en_GB/document_library/Scientific_guideline/2009/09/ WC500003920.pdf.

34 European Medicines Agency: Guideline on Similar Biological Medicinal Products Containing Monoclonal Antibodies: NonClinical and Clinical Issues. EMA/CHMP/ BMWP/403543/2010. 2012. http://www.ema. europa.eu/docs/en_GB/document_library/ Scientific_guideline/2012/06/WC500128686. pdf.

35 European Medicines Agency: Guideline on Non-Clinical and Clinical Development of Similar Biological Medicinal Products Containing Recombinant Erythropoietins. EMEA/CHMP/BMWP/301636/2008. 2010 http://www.ema.europa.eu/docs/en_GB/ document_library/Scientific_guideline/2010/04/WC500089474.pdf.

36 European Medicines Agency: Guideline on Similar Biological Medicinal Products Containing Interferon Beta. EMA/CHMP/ BMWP/652000/2010. 2011. http://www.ema. europa.eu/docs/en_GB/document_library/ Scientific_guideline/2012/01/WC500120652. pdf.

37 World Health Organization Expert Committee on Biological Standardization: Guidelines on Evaluation of Similar Biotherapeutic Products (SBPs). 2009. http://www.who.int/ biologicals/areas/biologicaltherapeutics/ B I O T H E R A P E U T I C S F O R WEB_22APRIL2010.pdf.

38 Wang J, Chow SC: On the regulatory approval pathway of biosimilar products. Pharmaceuticals (Basel) 2012;5:353-368.

39 Chugh PK, Roy V: Biosimilars: current scientific and regulatory considerations. Curr Clin Pharmacol 2014;9:53-63.

40 European Medicines Agency: European Public Assessment Reports (EPAR) for Human Medicines. http://www.ema.europa.eu/ema/index. jsp?curl=pages/medicines/landing/epar search.jsp\&mid=WC0b01ac058001d125.

41 Biosimilars Use in Europe. 2011.http://gabionline.net/Reports/Biosimilars-use-in-Europe.

42 Rompas S, Goss T, Amanuel S, Coutinho V, Lai Z, Antonini P, Murphy MF: Demonstrating value for biosimilars: a conceptual framework. Am Drug Health Benefits 2015;8:129139.

43 Grabowski H, Guha R, Salgado M: Biosimilar competition: lessons from Europe. Nat Rev Drug Discov 2014;13:99-100.

44 IMS Health: Shaping the Biosimilars Opportunity: A Global Perspective on the Evolving Biosimilars Landscape. 2011. http://www.imshealth.com/ims/Global/Content/Home $\% 20$ Page\%20Content/IMS\%20News/Biosimilars_ Whitepaper.pdf.

45 Ahmed I, Kaspar B, Sharma U: Biosimilars: impact of biologic product life cycle and European experience on the regulatory trajectory in the United States. Clin Ther 2012;34: 400-419. 
46 Jelkmann W: Biosimilar epoetins and other "follow-on" biologics: update on the European experiences. Am J Hematol 2010; 85:771-780.

47 Abraham I, MacDonald K: Clinical safety of biosimilar recombinant human erythropoietins. Expert Opin Drug Saf 2012;11:819-840.

48 Michallet M, Losem C: Biosimilar epoetin zeta in oncology and haematology: development and experience following 6 years of use. Acta Haematol 2016;135:44-52.

49 Haag-Weber M, Eckardt KU, Horl WH, Roger SD, Vetter A, Roth K: Safety, immunogenicity and efficacy of subcutaneous biosimilar epoetin- $\alpha$ (HX575) in non-dialysis patients with renal anemia: a multi-center, randomized, double-blind study. Clin Nephrol 2012; 77:8-17.

50 Seidl A, Hainzl O, Richter M, et al: Tungsteninduced denaturation and aggregation of epoetin alfa during primary packaging as a cause of immunogenicity. Pharm Res 2012;29: 1454-1467.

51 Biologics Price Competition and Innovation Act of 2009. 2009. http://www.fda.gov/downloads/Drugs/GuidanceComplianceRegulatoryInformation/UCM216146.

52 US Food and Drug Administration: Guidance for Industry: Biosimilars: Questions and Answers Regarding Implementation of the Biologics Price Competition and Innova- tion Act of 2009. 2012. http://www.fda.gov/ downloads/Drugs/.../Guidances / UCM273001.pdf.

53 US Food and Drug Administration: Guidance for Industry: Quality Considerations in Demonstrating Biosimilarity to a Reference Protein Product. 2012. http://www.fda.gov/ downloads/Drugs/GuidanceComplianceRegulatoryInformation/Guidances/ UCM291134.pdf.

54 US Food and Drug Administration: Guidance for Industry: Scientific Considerations in Demonstrating Biosimilarity to a Reference Product. 2012. http://www.fda.gov/ downloads/Drugs/GuidanceComplianceRegulatoryInformation/Guidances/ UCM291128.pdf.

55 US Food and Drug Administration: Guidance for Industry: Clinical Pharmacology Data to Support a Demonstration of Biosimilarity to a Reference Product. 2014 http://www.fda.gov/downloads/Drugs/ GuidanceComplianceRegulatoryInformation/Guidances/UCM397017.pdf.

56 US Food and Drug Administration: Guidance for Industry: Reference Product Exclusivity for Biological Products Filed Under Section 351(a) of the PHS Act. 2014. http://www.fda.gov/ downloads/Drugs/GuidanceComplianceRegulatoryInformation/Guidances/ UCM407844.pdf.
57 US Food and Drug Administration: Guidance for Industry: Labeling for Biosimilar Products. 2016. http://www.fda.gov/downloads/drugs/ guidancecomplianceregulatoryinformation/ guidances/ucm493439.pdf.

58 Wish JB: The approval process for biosimilar erythropoiesis-stimulating agents. Clin J Am Soc Nephrol 2014;9:1645-1651.

59 Fishbane S, Shah HH: The emerging role of biosimilar epoetins in nephrology in the United States. Am J Kidney Dis 2015;65:537542

60 Novartis Global: Sandoz Biosimilar Filgrastim Recommended for Approval by FDA Oncologic Drugs Advisory Committee [Media Release]. 2015. http://www.novartis. com / newsroom / media-releases / en/2015/1885139.shtml.

61 Pfizer Inc. FDA approves INFLECTRA ${ }^{\mathrm{TM}}$ (Biosimilar Infliximab), the First U.S. Biosimilar Monoclonal Antibody, for all Eligible Indications [Media Release]. 2016. http://www.pfizer.com/news/press-release/ press-release-detail/fda_approves_inflectra_ biosimilar_infliximab_the_first_u_s_biosimilar_monoclonal_antibody_for_all_eligible indications.

62 Mulcahy AW, Predmore Z, Mattke S: The Cost Savings Potential of Biosimilar Drugs in the United States. 2014. http://www.rand.org/ content/dam/rand/pubs/perspectives/ PE100/PE127/RAND_PE127.pdf. 